\title{
A Filosofia Econômica do Valor
}

\author{
FRANCISCO JoSÉ DE SouzA
}

\begin{abstract}
A Revista do Serviço Público está em débito para com Francisco José DE SouzA. Apesar de ser êste o seu $3^{\circ}$ trabalho por nós publicado, sòmente agora divulgamos seu «curticulum vitae», - que fazemos num preito de reconhecimento aos seus esforços de profundo pesquisador nos assuntos de sua especialidade; Bacharel em Direito pela Faculdade de Recife, Economista, Contador do Ministério da Fazenda, por mais de dez anos regeu a cadeira de «Valor e Formação de Preşos», no curso de Economia da Faculdade de Ciências Econômicas da Universidade Católica de Pernambuco.

Redigit em todos os jornais do Recife, nas revistas «Nordeste» e «Symposium». Na Guanabara tem colaborado na «Revista do Serviço Público», na «Revista de Finanças Píblicas» do Consetho Técnico de Economia e Finanças do Ministério da Fazenda, no "Boletim da Contadoria Geral dă República" e no «Mensário Brasileiro de Contabilidade». Antigo associado do IDORT, de São Paulo, escreveu, igualmente, para a «Revista de Ciências Econômicas». - NOTA DA REDAÇAOO.
\end{abstract}

\section{I - O VALOR EM ECONOMIA POLITICA}

\section{$\mathrm{E}$}

m matéria de valor econômico, a dificuldade do expositor está em ser impossivel a sintese, dada a imensidade de escritos, de teses, de refutações, de revisões, a par de grande número de teorias, que se propõem explicar o valor.

Abstrata, por natureza, a matéria do valor tem dado «dor de cabeça» aos economistas. Daí a desolada advertência de CHARLES GIDE (1) de que a questão do valor em Economia Política, não obstante a aparência de simplicidade, se constituiu, há séculos, o tormento dos economistas.

Nenhuma outra querela se lhe compara, nem mesmo a controvérsia sôbre o método, em Economia Política, suscitada por

(1) Charles Gide - Compêndio de Economia Politica. Livr. do Globo, 
É que, tendo chegado a ser identificado com a própria Economia Política, o valor passou, no comêço do século XX, a ser severamente combatido, acoimado de «nostalgia metafísica», sendo até proposta a sua exclusão da ciência econômica, pelos chamados negativistas.

Alegava-se que a teoria positiva teria de se limitar ao estudo da formação do preço-de-mercado, por ser um problema objetivo e, portanto, de certeza. Donde a reviravolta: o problema central da teoria econômica seria o preço, e para outros o próprio objeto da ciência econômica. Assim, os partidários da teoria do preço justificavam-se alegando que o estudo do valor implicava em conjecturas filosóficas e psicológicas; que a pretensão de investigar a causalidade (princípio de causa e efeito) e a teleologia (fins) do valor, ou mesmo o seu fundamento, seria uma eterna discussão bisantina.

Stanley Jevons, por exemplo, sugeriu fôsse banida a palavra - valor - da Economia Politica; Aupetit a considerava destinada a desaparecer do vocabulário científico; Ch. BrouILHET achava-lhe apenas uma significação «artística»; Antonelli não admitia o valor na Economia Pura; Ch. Bodin julgou desnecessária a noção do valor; Brousquet sentenciava ser tempo perdido dedicar-se o economista ao «misterioso valor» e, por fim, CASSEL (2) julga supérflua a teoria do valor, estudando, de logo, a formação e movimento dos preços.

O prof. GaËtan PIRou (3) explica que essa investida frontal à teoria do valor justificava-se pelo «caráter conjectural» da pesquisa do valor, que pertence ao domínio do incerto, do indemonstrável, do inverificável, e que o máximo a se obter seria um grau de verossimilhança ou probabilidade, mas incapaz de se transformar em certeza».

Contudo, o problema do valor continua a ser pesquisado e amplamente discutido nos torneios da Filosofia Econômica, não sendo poucos os seus modernos defensores. Dentre êles sobressaem os dois Turgeon (Charles et Charles Henri), que consideraram a noção do valor a idéia central da Economia Política. Françors PERrox admite ser o preço a expressão de uma realidade mais profunda e geral - o valor.

De maneira que, opina PIRou (ob. cit.) - se admitiu o dualismo na teoria econômica: valor e preço, quer dizer, a análise abstrata (o valor) e a sintese concreta (o preço).

(2) Gustavo Cassel - Economia Social Teórica. M. Aguillar, Editor, Madrid, 1946.

(3) Gä̈tan Pirou - La Valeur et les Prix Edition Recueil Sirey, Paris 1948. 
O valor, na ciência econômica, é um juizo, uma estima, uma importância atribuida ao bem, pelo homem e resulta da «comparação seletiva».

Todavia não é um têrmo especifico ou exclusivamente econômico. A noção do valor transborda do quadro da Economia Política. Há a axiologia ou ciência dos valôres. No plano geral da compreensão êle é político, econômico, moral, religioso, artístico, etc. Contreiras Rodrigues (4) considera o valor «uma relação humana; uma categoria universal. A noção do valor é analógica e não univoca». Pelo que o define em acepção ampla: «O valor é o mérito que se atribui às coisas e atos humanos, em vista do fim para que são aptos e a que se destinam».

PAPATERRA Limong (5) vê no valor o duplo aspecto:

«a) em sua natureza, isto é, em sentido absoluto, é físico, moral, intelectual, etc.;

b) em sentido relativo, extrínseco, sob a forma econômico-racional, de poder aquisitivo, o conceito de valor é qualitativo de causa, segundo uns, encontrada na utilidade, outros na limitação, e ainda outros na combinação de ambas (utilidade - rara)».

Etimològicamente, o vocábulo valor origina-se, segundo a1guns autores, do substantivo latino «valoris». ALMmeidA Nogueira (6) porém, discorda dessa procedência, observando que o vocábulo «valor, is» não é latim nem se encontra nos léxicos dêsse idioma, defendendo, então, como de boa latinidade o verbo «Valere», que, dentre outras significações, corresponde à do nosso vernáculo «valer».

\section{II - ESCÔRÇO HISTÓRICO DO VALOR}

$\mathrm{Na}$ prospecção histórica podemos distinguir duas grandes fases das concepções do valor: as antigas, compreendendo as idéias dos precursores de Adam Smith, desde a antiguidade clássica até os fisiocratas; e as modernas, da fase científica da Economia.

Por exemplo: quem manusear «A Política», de ArIstóteles, (7) há de verificar que a primeira parte é dedicada à análise da

(4) F. Contreiras Rodrigues - Conceito de Va'or e Preço. Co-editora
Brasília, Rio, 1942.

(5) Papaterra Limongi - Economia Politica. Livr. Freitas Bastos,
Rio 1950.

(6) Almeida Nogueira - Curso Didático de Economia Política. Gráfica São José, S. Paulo, 1936, pág. 285.

(7) Aristóteles - A Politica. Atena Ėditôra, S. Paulo. 
base econômica da sociedade. Dos demais estudos de Economia do sábio estagirita só se conhecem fragmentos. Assim, é no citado livro que colheremos a melhor visão do pensamento econômico da Grécia antiga, mormente no que diz respeito ao valor. Ali se encontra a mais velha divisão do valor: valor de uso e valor de troca. Debatendo essa dualidade, com o clássico exemplo do par de calçados, o Peripatético inclina se pela preeminência do valor de troca.

$\mathrm{Na}$ Média Idade, os teólogos e doutôres da Igreja, salientando-se S. Tomás de Aquino, Santo Alberto, o Grande, Raimundo de Pennafort e Buridan, êste reitor da Universidade de Paris, dedicaram-se ao debate ontológico do valor e do preço, sendo dessa fase a teoria do «usto Preço», impregnada dos nobres ideais de justiça comutativa e distributiva.

Nos séculos XVII e XVIII, o racionalismo filosófico, enciclopédico, dedicou suas especulações, de forma febricitante, à Economia, como se fôra a «Panacéia Universal» que viria solucionar todos os problemas sociais. Daí o aparecimento da Fisiocracia ou Govêrno da Natureza, que ostenta o invejável título de primeira escola econômica e em que aparece, pela primeira vez, a expressão - economista - para designar os estudiosos da nova ciência.

Acontece, porém, que, no tocante ao valor, os fisiocratas fizeram apenas indagaçóes perfunctórias receosos, talvez, da complexidade do valor. Para os seguidores do Dr. Quesnay, que viam na Agricultura a única atividade verdadeiramente econômica, vale dizer, produtiva, rotulando de estéreis as demais classes sociais, o valor provinha do trabalho da terra.

Contudo, mantém-se a divisão do valor de uso e valor de troca, havendo evidente confusão entre êste e o preço e entre utilidade e valor de uso. Outrossim, tendo havido dissidência na «escola», pela formação da ala dos subjetivistas, encontramos essa discordância na concepção do valor, segundo as duas correntes antagônicas.

Para LE Trôsne, adepto das idéias do Dr. Quesnay, "o valor consiste na relação de troca entre uma coisa e outra», enquanto que, para Turgot, - «o valor é a expressão do grau de estima, que o homem afeta aos diversos objetos de seus desejos» (Apud Contreiras Rodrigues, ob. cit., pág. 78). No primeiro conceito tem-se uma adequação objetiva, enquanto no segundo êle é nitidamente subjetivo e, dir-se-ia, impregnado de psicologia econômica.

Ainda, caberia aqui mencionar os precursores inglêses, com William PETty à frente, mas, pelo que expusemos, já se pode 
ter uma noção do pensamento «pré-científico» da Economia, no que se relaciona com o valor.

Passaríamos, então, a expor as concepções modernas, a partir de Adam Smith. Não o faremos agora, porque, segundo o plano a que êste trabalho obedece, teremos o ensejo de nos deter, adiante, nas principais teorias do valor que são pertinentes ao ciclo científico.

\section{III - AS FORMAS DO VALOR: DE USO E DE TROCA}

Já vimos que a divisão remonta aos estudos do «fundador da ciência antiga», como, de justiça, alcunhou-se Aristóteles. A persistência na dicotomia revela duas orientações distintas e, por vêzes, agressivamente antagônicas.

Para os defensores do objetivismo na Economia Política, como ciência, notadamente os clássicos liberalistas e os socialistas, se bem que não ignorassem o valor de uso, confundiam-no com a utilidade. Daí só considerarem a típica revelação do valor como fato social, ou seja, resultante ou emergente das relações de troca, quando esta se concretizava através da oferta e procura.

De conseguinte, só o valor de troca mereceria as honras da ciência. Adam Smith (8) fala do valor «em uso» e «em troca», expressões substituídas, ao que parece, por J. B. Say, para valor de uso e valor de troca. KARL MARx (9) também não nega o valor de uso, mas o considera apenas «el soporte material do
valor de troca».

Nos fins do XIX século é que aparece, com os marginalistas, a reação contra a teoria clássica, com a elevação do valor de uso ou teoria subjetiva do valor, psicológica e matemática, aos píncaros da verdade cientifica, ensejando o aparecimento de uma infinidade de escritos, todos visando à cabal explicação do fundamento do valor, alvo talvez inatingivel.

De forma que, enquanto os adeptos da teoria clássica tomavam por base a oferta e as «condições de produção», os subjetivistas partiam do pressuposto de que o verdadeiro valor deveria ser encontrado do «lado do consumidor».

O valor de uso, por uns chamado valor subjetivo, por outros, valor individual, representa a importância atribuida a um bem, isto é, representa apreciações ou estimas individuais. Já o valor de troca, também chamado valor objetivo e valor social, não obstante representar igualmente uma importância, refere-se às

(8) ADAM SMith - A Riqueza das Nações.

(9) KarL MARX - O Capital (Vol. I, T. 1) Fondo de Cultura Econó-
mica (México). 
apreciações ou estimas coletivas. No primeiro caso, verificar-se-ia a Economia Individual, no segundo, a Economia Social. (Cfr. G. Pirou, ob. cit.).

\section{IV - AS TEORIAS DO VALOR}

Não há uma classificação única, uniforme, das teorias do valor. Ainda aqui se nota a dificuldade para o expositor. Com efeito, vejamos o que nos diz o antigo professor da Faculdade de Direito de São Paulo, sôbre o assunto:

«Nenhuma classificação conhecemos, que seja satisfatória, dos diversos sistemas sôbre a noção e os fundamentos do valor, e muito distam da uniformidade, neste ponto, as tentativas que se encontram nos trabalhos didáticos dos economistas». ( Cfr. Almeida Nogueira, ob. cit., pág.287).

Não obstante, embora reconhecendo que o «defeito capital da nossa classificação está em não obedecer a mesma a um princípio divisor comum», propõe sejam as teorias do valor «classificadas em seis sistemas capitais», a saber:

I - Teoria clássica

II - Teoria socialista

III - Teoria utilitária

IV - Teoria matemática

$\mathrm{V}$ - Teoria psicológica

VI - Teoria objetiva

Já Contreiras Rodrigues (ob. cit., pág. 65) partindo do dualismo - objetivismo e subjetivismo - defende a seguinte classificação:

a) Teorias subjetivas:

I - Valor estimativo

II - Valor utilidade

III - Valor oferta e procura

IV - Valor utilidade-final

b) Teorias objetivas:

I - Valor trabalho
II - Valor custo de produção
III - Valor custo de reprodução.

Por sua vez, o prof. Louis Baudin (10) se atém a uma orientação cronológica, supomos, ao alinhar as teorias do valor na seguinte ordem:

(10) Lours Baudin - La Monnaie et la Formation des Prix. Recueil Sirey. Paris, 1947, 2 Ed., Pág. 29. 


\section{I - Valeur travail}

II - Valeur côte de production

III - Valeur côte de reproduction

IV - Théories pluralistes

$\mathrm{V}$ - Théories négatives

VI - Théories fonctionelles

VII - Théories marginalistes.

Dessas classificações, que aí ficam alinhadas, duas são as teorias proemientes, pela importância do conteúdo perceptual e também porque, sôbre representarem os pontos de vista das correntes ditas objetivistas e subjetivistas, têm nas demais teorias simples variantes. Queremos nos referir, é claro, à teoria do trabalho-valor e à teoria do valor explicado pela utilidade-final, limite ou marginal.

Levando em conta essas razões e mais as do limite desta ordem expositiva, que vimos adotando e seguindo, somente elas estudaremos, por ora.

\section{$\mathrm{V}$ - A TEORIA DO VALOR-TRABALHO}

Partindo da lei da divisão do trabalho e admitindo-se o pensamento de Smith, de que «com o trabalho é que tôdas as coisas foram inicialmente compradas», verificaremos a primazia, ou procedência do trabalho como fonte primeira do valor, se bem que não desconheçamos a tendência moderna de repelir as teorias unicausais, increpadas de um primarismo que, em absoluto, não avalisamos. Seja como fôr, essa orientação não pode elidir a preferência dedicada ao trabalho ou esfôrço humano, como «subs tractum» do valor. Depois, a teoria, sociològicamente, é das mais importantes, pelo desenvolvimento e ressonância alcançados pelo Marxismo.

De fato, é essa uma particularidade interessante: formulada ou, pelo menos, exposta por corifeus do liberalismo politico e econômico, pelos chamados clássicos da economia burguesa, como Adam Smith, Malthus e Ricardo, foi tomada pelos socialistas, tanto os utópicos como os científicos.

Para Adam Smith a palavra valor tem significação dupla: ora representa a utilidade (valor de uso) de um objeto particular, ora a faculdade que dá a posse dêsse objeto para adquirir (valor de troca) outras mercadorias.

É com David Ricardo, entretanto, que o trabalho, como fundamento do valor, adquire maior consistência a despeito da póuca 
clareza com que expôs as suas idéias. Iniciando o Cap. IV de sua obra capital, (11) RiCARDO proclama:

«Al considerar el trabajo como fundamento del valor de los produtos y la cantidad relativa de trabajo necessária a su producción, la ley que determina las respectivas cantidades de mercancias que seram dadas al intercambiarse, no se ha de suponer que negamos las desviaciones accidentales y temporarias del precio de mercado de los produtos respecto de aquel, que es su precio originário y natural».

Temos, então, que, para RICARDo, o «preço natural» identifica o valor intrinseco do produto, representado pelo trabalho ou pela «quantidade relativa de trabalho necessário», se bem que possa diferir, acidental e temporàriamente, do preço de mercado do mesmo produto, pela interferência ou oscilações oriundas da oferta-procura.

A segunda concepção do valor-trabalho é a desenvolvida pelos socialistas, mas, neste estudo, apenas relataremos a teoria formulada e desenvolvida pelo fundador do socialismo científico (com Rodbertus), que foi KarL Marx - «o último grande economista da Escola Clássica, como o qualificou, acertadamente, Charles Gide. (12)

MarX, em crítica magistral ao processo de produção da economia burguesa e à dinâmica de suas relações, iniciada pela «Contribuição à Crítica da Economia Política» (13) e concluída pelo «Das Kapital» vale-se do trabalho como «causa» do valor, refundindo em moldes definitivos a teoria dos clássicos em novas e mais fortes bases, mercê do seu inegável vigor intelectual e à surpreendente visão científica, que impôs sobrevivência às suas idéias.

Partindo do conceito de mercadoria como «forma elementar da riqueza», MARX aceita a divisão clássica do valor, para chegar à conclusão, de que,

«como valôres de uso, as mercadorias são, antes de tudo, de qualidade distintá; como valôres de troca, só podem ser diferentes em quantidade»,

e, nessa ordem de raciocínio e considerando que a «substância do valor é o trabalho e a sua medida a duração do trabalho», MARX

(11) David Ricardo - Princípios de Economia Politica y Tributación.

Editorial Claridad, Buenos Aires, 1941, Pág. 59.
(12) Gide ET RIST - História das Doutrinas Econômicas. Editôra Atlas, Rio, 1941.

(13) KARL MARX - Contribuição à Crítica da Economia Politica. Editôra Flama Ltda., S. Paulo, 1946. 
chega à construção ou enunciado de sua famosa fórmula do valor: $\mathrm{V}=\mathrm{c}+\mathrm{v}+\mathrm{pv}$, ou seja: Valor $=$ capital constante + capital variável + plus valia ou lucro.

Explicando-a, Marx ensina que o valor de um produto é igual ao capital constante representado pela soma em dinheiro invertida em meios de produção mais o capital variável, também soma em dinheiro aplicado em fôrça de trabalho, mais, finalmente, o sôbrevalor ou mais valia, que é «a expressão exata do grau de exploração da fôrça de trabalho pelo capital ou do operário pelo capitalista» (Cfr. O Capital, loc. cit., pág. 241, T. I. V. 1).

Quanto ao valor de uso, é a utilidade que lhes dá essência, se bem que «a utilidade dos objetos não flutua no ar». Por isso, «un valor de uso, un bien, solo encierra um valor por ser encarnación o materialización del trabajo humano abstracto. Como se mide a magnitud de este valor? Por la cantidad de «substancia» criadora de valor, es decir, de trabajo, que encierra». Logo, conclui MARX - «lo que determina la magnitud do valor de un objeto no es más que la cantidad de trabajo socialmente necesario para su producción».

Como se observa, a linguagem de Marx é, «mutatis mutan dis» a de DAvid RicARDo, mas, em face das conclusões (embora conseqüentes, ou por isso mesmo?) a que chegou o genial judeualemão, sua teoria sôbre «o processo da formáção do capital» tem sido golpeada pela crítica, às vêzes cega e quase sempre infundada, seja dos chamados «revisionistas» à moda de Bernstein, seja dos sociólogos, à feição de Giddings, e, precipuamente, dos economistas partidários do neoliberalismo ou do «capitalismo evoluído ou saneado» a que chegou John MAYNARD KEYNES (14).

Contra ela (a teoria do trabalho-valor) investiram de modo acerbo os subjetivistas, no terreno da Economia, enquanto que, politicamente, não pode haver, parece, conciliação entre as duas correntes de pensamento, porque representam sistemas filosóficos ou, mais simplesmente, "way of life». Amostra típica dessa contestação à teoria do valor de Karl Marx é a série de objeções apresentadas pelo prof. Louis BAudin (15), e, em essência, reproduzidas por Matos Peixoto (16), em lúcida monografia:

1. $\left.{ }^{\circ}\right)$ Vendem-se no mercado e têm valor coisas em que não se acha incorporado nenhum trabalho (a terra,

(14) AlAIN BARRère - Keynes e o Futuro do Capitalismo. Livraria Progresso Editôra. Bahia, 1958. (15) Louis Baudin - Précis d'Histoire des Doctrines Economiques.
Edition Domat, Paris, 1949. (16) Matos Peixoto (Almir da Câmara) - O Valor em Ecoñomia
Politica. Organização Simões, Rio, 1951. 
as pedreiras, os sítios naturais, fontes de água mineral, jazidas de petróleo);

$\left.2 .^{\circ}\right)$ a trabalhos iguais podem corresponder valôres distintos (um quilo de filet e um quilo de lombo de um mesmo boi abatido; vinhos e frutos em que se versou igual trabalho; quadros pintados pelo mesmo artista, num mesmo tempo);

$\left.3 .^{\circ}\right)$ objetos mudam de valor no tempo, sem que nôvo trabalho a êles se ajunte (o vinho velho, edificios), e

$\left.4^{\circ}\right)$ há objetos cujo valor se fixa sem ser levado em consideração e sendo desconhecido o tempo de trabalho que custaram (objetos de belchior; antigüidades).

Essa «contradição pelos fatos» como se expressa o prof. Baudin., ob., cit.) não pode ser acolhida pelo estudioso da obra de MARX, porque é totalmente dissociada da idéia central que norteou o fundador do Marxismo ao edificar sua teoria do valor. Revela, «à rebours», a paixão ante a impossibilidade de isolar a Economia da Política, resultando debalde o conselho de MAx WEBER no sentido da separação, quando se deseja discutir a ciência, que, «coeteribus paribus», é despida de preconceitos.

O que, em verdade, nos parece, é que Marx tinha de aceitar o trabalho como regra geral ou causa material para que algo se convertesse em um bem econômico e, por isso, em valor. Os seus contraditores argúem com exceções, com fatos isolados, como se uns e outros pudessem invalidar a generalidade, quando, ao contrário, a confirmam.

Tanto isso é certo, que, na própria obra de MARX ( e. g. - O Capital) encontram-se argumentos de rebate às críticas apressadas. Por exemplo, êle não cai no êrro de tantos economistas, que confundem valor com o preço. Um objeto, um bem econômico, enfim, pode ser vendido abaixo do custo (valor real), mas, nesse caso, já se trata de uma operação, digamos, mercantil, de especulação e, em suma, sujeita aos fatôres psicológicos que influem na oferta-procura. Por isso, advertia MARX - «Diversas são as causas pelas quais variam os preços...» (Apud Matos Peixoto, ob. cit., pág. 88 ).

E o mesmo autor assim conclui sua apreciação sôbre a teoria marxista: «O valor, para Marx, é uma relação social. Provém do trabalho produtivo. No regime capitalista, o trabalho vivo invertido nos produtos reproduz o valor da fôrça do trabalho do operário e produz um sôbre-valor ou mais valia» (Ob. Cit., pág. 89). 


\section{VI - A TEORIA MARGINALISTA DO VALOR}

A chamada teoria moderna do valor, baseada na utilidadelimite, é, no dizer dos tratadistas, a síntese do valor utilidade e do valor raridade, ou, como quer Gide, aliás com muita propriedade, o nome erudito de utilidade-rara. Representa, como veremos, uma nova direção nos estudos do valor econômico, fundada na supremacia do valor de uso até então relegado a plano secundário pelos economistas da escola clássica e seus continuadores.

Os fisiocratas, sabemos, identificavam o valor de uso com a utilidade, ou mais claramente: do lado do consumidor é que se deveria procurar o fundamento do valor. Em conseqüência dessa investigação, chegamos a saber que o valor de troca se origina do valor de uso, que tem por fundamento a utilidade. Eis, portanto, exposta sucintamente, em sua essência, a antiga teoria do valor -utilidade.

O prof. Gä̈tan PIROu ( $b$. cit.) salienta nesta teoria, den tre os antigos, o fisiocrata Condillac, para quem o valor das coisas tem fundamento "em sua utilidade, ou, no que vem a ser o mesmo, em nossas necessidades, ou, ainda, no uso que podemos fazer delas». Porque, prossegue Condillac, «é preciso lembrar que as coisas têm valor porque suas qualidades são próprias para o nosso uso», isto é, "se não as julgássemos "com essas qualidades, elas não teriam valor algum».

O desenvolvimento dessa concepção de utilidade-valor, por Galiani e Condillac, salienta o prof. Pirou, leva os a encontrar um co-fundamento do valor na raridade ou rareza. E' que a economicidade das coisas está em sua rareza (ou raridade, como preferem outros). Já para o prof. CAssel (ob. cit.) é o principio da escassez, que, plasmando a noção do útil, vai dominar o conceito de bem econômico. Vejamos, porém, a explicação por Montanari, do conceito econômico de raridade: «econômicamente, as coisas são raras porque existem em quantidades insuficientes para satisfazerem as nossas necessidades». Donde se conclui que «a raridade é uma proporção entre a quantidade e o desejo dos

Todavia, o acréscimo da noção de raridade como co-fundamento do valor veio mostrar a incapacidade dos fisiocratas de construirem uma teoria homogênea do valor. Esse esfôrço de harmonização dos conceitos de utilidade e de raridade na formação do valor coube, no dizer do prof. Pirou, aos fundadores
do marginalismo.

Numa visão sumária, diremos que o marginalismo surgiu, em 1871, na Inglaterra, com a publicação do livro de Stanley Jevons: 
«The Theory of Political Economy»; no mesmo ano, na Áustria, apareceu o livro de Karl Menger, fundador da «escola austríaca» sob o titulo de «Grundsatze der Volkswirtschaftslebre», no qual, segundo afirma Joseph A. SCHUMPETER (17) - «apresenta-nos a grande reforma da teoria do valor». Em 1873, LÉON WALRAS dá a conhecer a sua monumental - «Théorie Mathématique de l'Échange», realçando a importância da Economia Pura e elaborando a teoria do equilibrio econômico, para chegar «a pedra fundamental de sua estrutura, o conceito da utilidade marginal», como explica Schumpeter (ob. cit.).

Stanley Jevons, tomando os estudos de Gossen e Cournot, lança as bases da "escola matemática», que se consolida com Walras e seus seguidores, pela aplicação do método matemático à análise econômica.

A outra direção se deve a KARL MengER, com a aplicação do método psicológico na análise da satisfação das necessidades, seguido por BöHM-BAWERK e WIESER.

Essa singular «confluência intelectual» assinalada por ALAIN BARRÈRE (ob. cit.) também o foi por-Schumpeter (ob. cit.) que, referindo-se aos trabalhos de WALRAS, assim se expressa: «A concordância dos seus resultados com os de Menger e Jevons é tão surpreendente quanto as diferenças dos pontos de partida e métodos respectivos».

Nos EE. UU. a teoria logrou ampla repercussão graças à adesão dos economistas norte-americanos, a partir de J. B. CLARK, com Fettre, Seligman, Fischer e outros, sujeita embora à influência do institucionalismo.

Tendo em conta a diversidade de autores e bem assim o aparecimento quase simultâneo das concep̧̧ões do valor com base no binômio utilidade-raridade, há tratadistas que expõem a matéria sob a epígrafe de «teorias modernas do valor» (Cf. PIRou, ob. cit.) e outros as qualificam de «teorias marginalistas do valor» (Passim, Baudin, ob. cit.).

Com efeito, deve-se a WIESER a expressão «utilidade-limite» (Grenznutzen), enquanto JEVons chamava-a «último grau da utilidade» (final degree of utility) e WaLras «raridade» (rareté). Em França, adotava-se a expressão «utilité finale» (utilidade final) e nos EE. UU. davam-se-lhe a denominação de «utilidade marginal», que, por fim, triunfou sôbre as demais.

Matos Peixoto, em seu excelente ensaio sôbre o «Fundamento do Valor em Economia Política», explica que «Utilidade

(17) Joseph A. Schumpter - 10 Grandes Economistas. Ed. Civilização Brasileira, Rio, 1958. 
marginal é a utilidade da última unidade, dose ou exemplar de um dado estoque de bens». (ob. cit.).

Para Contreiras Rodrigues ( $o b$. cit.) a tese da utilidadefinal surgiu da observação de Stanley Jevons de que - «os juízos de valor são juízos de comparação e não se referem a gênero, mas a fraçốes reais de quantidades precisas de cada gênero, em um momento determinado e em um ponto determinado do espaço». E', nada mais, do que a aplicação da chamada «teoria da curvatura do espaço econômico». Eis porque, assinala, para Jevons, - «a utilidade ou valor dependem do desejo, da quantidade, do tempo e do espaço».

A utilidade, para Jevons, explica aquêle autor, é total e parcial. Parcial, marginal, limite ou final é a quantidade ou porção que cada indivíduo carece para satisfazer as suas necessidades. A utilidade seria a soma das unidades.

Todavia, a teoria subjetiva do valor foi melhor exposta e desenvolvida por MENGER, com a técnica da psicologia ou método psicológico aplicado à análise das teorias econômicas dos bens, das modalidades do valor e da hierarquia das necessidades e satis-
fações.

Há, para MENGER, várias espécies de bens: de primeira, segunda, terceira e quarta ordens. Os de primeira ordem (o pão, por exemplo) são direta e imediatamente aplicados na satisfação de uma certa necessidade. Já os de segunda ordem servem para dêles se obter os de primeira, como a farinha de trigo. Assim, perquirindo a esteira da produção, encontraríamos os bens de terceira ordem (o trigo, por exemplo) e os de quarta, que, seriam o campo, $o$ arado, etc. (Cf. Pirou, ob. cit.).

Embora MENGER aceitasse a divisão clássica do valor (de uso e de troca), BöHM-BAwErk a substituiu pelas expressões «valor subjetivo e valor objetivo», cuja síntese seria o «valor econômico», ou seja, «dos dois valôres aquêle que melhor permita a satisfação da necessidade e que tanto pode ser um como outro».
(Cf. PIRou, ob. cit.).

Contudo, desenvolvendo a concepção de valor de uso e valor de troca, BöHM-BAwERK distingue dois valôres subjetivos e dois
objetivos, a saber:

a) Valor de uso objetivo - que é a propriedade que têm os bens de servirem a fins úteis, como a lenha, que nos serve
porque desprende calor;

b) Valor de uso subjetivo - que é a importância atribuída aos bens aptos a provocarem o nosso bem-estar imediato; 
c) Valor de troca subjetivo - que é a importância atribuída a um bem, porque se troca e permite adquirir outro mais útil, e

d) Valor de troca objetivo - que é a expressão quantitativa do valor de troca subjetivo; é o preço que obtém êste valor no mercado, depois de ser calculado subjetivamente. (Apud CoNTREIRAS RODRIGUES, ob. cit.).

Interpretando o pensamento de BöHM-BAWERK, escreve CoNTREIRAS Rodrigues (ob. cit.) : «O valor de uso subjetivo é o fundamento da teoria psicologista; é o valor, por excelência, aquêle que se distingue da utilidade, pois que coisas muito úteis podem ter pouco valor, como a água; ou muito valor com a mesma utilidade, como a água mesma. Üm copo dágua por $\operatorname{NCr} \$ 1,00$ tem a mesma utilidade que outro de NCr\$ 0,10 . Este valor decorre da noção de utilidade marginal e esta da quantidade da riqueza; e é igual a essa utilidade limite multiplicada pelo número de vêzes que a mesma quantidade total contém a utilidade final» (pág. 128, ob. cit).

O terceiro elemento básico para a compreensão do marginalismo é a hierarquia das necessidades e das satisfações. De um modo geral, aceita-se a classificação assim ordenada: alimentação, habitação, vestuário e de confôrto ou luxo. Donde a conclusão da teoria psicologista de que «para um dado indivíduo, em um momento dado, há uma hierarquia de necessidades».

Essa concepção hierárquica das necessidades ou desejos se completa com a «Lei das satisfações decrescentes» ou da «utilidade decrescente», também chamada lei de Gossen, citada por Alde Feijó SAmpaio (18): «uma satisfação, qualquer que seja, se é prolongada, decresce, acaba por desaparecer e se transforma em dor ou constrangimento».

Por sua vez, J. Dumarchey, (19) em seu vigoroso e concludente estudo expositivo da teoria do valor com fulcro na utilidade marginal, serve-se dos exemplos de BöHM-BAWERK (teoria psicologista) e de LEÓN WALRAS (teoria matemática).

A explicação de BöHM-BAWERK, com base na utilidade-limite, é a seguinte:

«Um colono que vive longe do mundo possui cinco sacos de trigo. Ûm dêsses sacos é-lhe rigorosamente necessário, até a próxima colheita; um segundo saco é-lhe ainda necessário, como complemento de ração; um terceiro saro servirá para alimento das suas aves de

(18) Alde Feijó Samparo - Economia Circulatória e Economia Repartitiva. Editôra Atlas, Rio, 1944.

(19) J. Dumarchey - Teoria Positiva da Contabilidade. Ed, da Revista de Contabilidade e Comércio, do Pôrto, Portugal. 
capoeira; um quarto, para fabricar aguardente; e um quints saco, finalmente, para alimentar papagaios que o divertem. O valor de cada saco de trigo corresponde a um número que tem a propriedade de exprimir, com singeleza ou clareza, a hierarquia das necessidades ou desejos:

$1 .^{\circ}$ saco $=16$

$2 .^{\circ} \gg=8$

$30^{\circ} \gg=6$

$4 .^{\circ} \gg=4$

$5 .^{\circ} \gg=1 . \gg$

«Se o colono (continua expondo Dumarchey) vende um saco de trigo, o que venderá será o que se destina ao papagaio, que vale 1; BöHM-BAwerk conclui que o valor de cada saco de trigo será determinado pelo saco que serve para alimentar os papagaios, porque, se os sacos são iguais uns aos outros, será absolutamente indiferente para o colono perder o saco $\mathrm{A}$ ou $\mathrm{B}$, contanto que fiquem ainda, por detrás do saco ido, quatro outros sacos, para satisfação das necessidades mais importantes».

A exemplificação de Walras, por meio da lei de Gossen - «as satisfações são decrescentes», se expõe dá seguinte forma:

«Se eu sinto uma necessidade qualquer, a primeira unidade quantitativa do produto próprio para a satisfação dessa necessidade terá para mim um certo valor; se a esta primeira unidade se junta uma segunda, o valor desta será inferior ao que tinha a primeira. Todavia, o valor das duas juntas não será igual à soma dos valôres tomados separadamente, mas sim igual ao dôbro da segunda. No entanto, poderemos escolher esta unidade quantitativa de tal maneira, que o valor da segunda seja superior à metade do da primeira, de modo que o valor das duas unidades será superior ao de uma apenas».

Juntemos uma terceira unidade à segunda. $O$ seu valor será ainda inferior, mas poderá fazer-se com que o valor total da existência, igual a três vêzes o último valor, seja ainda superior ao valor das duas primeiras. Contudo, se continuarmos a juntar uma quarta unidade, uma quinta, etc., acontecerá que o valor total ou marginal da existência passará por um máximo a partir do qual decrescerá» (ob. cit., pág. 73).

No primeiro exemplo a utilidade total seria representada pelo número cinco (5), quer pela definição de Wieser - «a utilidade 
total é igual à utilidade final multiplicada pelo número de objetos»- $(1 \times 5=5)$, quer como a entende BöHM-BAwERK - «a utilidade total representa a soma das utilidades dos objetos» - no caso: $1+1+1+1+1=5$.

Entretanto, para o segundo exemplo, a compreensão não é tão clara, pelo que aduzimos o seguinte: se à primeira unidade dermos 16 à sua utilidade marginal, 10 à segunda, 8 à terceira, 6 à quarta e 4 à quinta, obteremos o seguinte resultado:

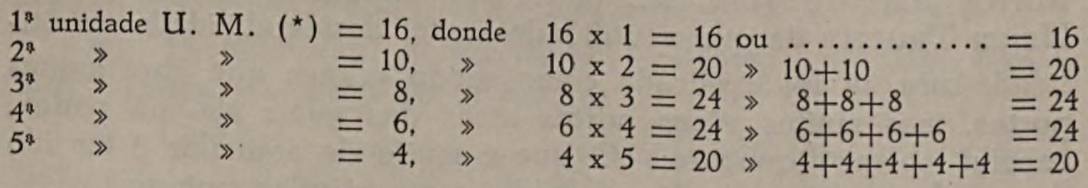

(*) Utilidade Marginal.

Tendo em vista, porém, a dificuldade no entendimento do que seja utilidade marginal e utilidade total, permitimo-nos insistir na demonstração, recorrendo à apresentação de um outro exemplo, elaborado pelo prof. Baudin (ob. cit.): Sejam onze frações de um bem cuja utilidade marginal decresce de uma unidade; a utilidade total da primeira fração será igual à sua utilidade marginal representada por 10; a segunda fração terá 9 por utilidade marginal e, como as duas frações são permutáveis entre si, a soma das duas frações resultará 18; prosseguindo-se nos cálculos, obteremos o seguinte quadro:

$\mathrm{N}^{\circ}$ de unidades

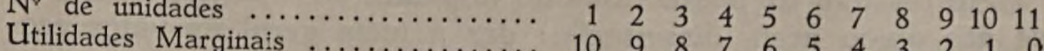

Utilidades totais ...................

Dessa demonstração resulta confirmado o fato já observado de que a utilidade total cresce até um máximo e depois decresce. O zero representa os dois extremos: o de partida correspondente à ausência total do bem considerado para retornar ao zero que resulta da superabundância dêsse bem. Na expressão de SELIGMAN, o zero marca o limite entre o mundo econômico e o não econômico. (Cfr. Baudin, ob. cit.)

JEvons exprimiu a lei geral do seguinte modo: «o grau de utilidade varia com a quantidade de uma mercadoria e diminui quando essa mercadoria aumenta». WaLras, igualmente, expõe: «a intensidade da última das necessidades satisfeitas por uma quantidade de mercadorias consumidas (..) é uma grandeza que decresce à medida que a quantidade aumenta» (idem, ibidem). 
Pela exposição feita na teoria da utilidade final, limite ou marginal, chega-se à conclusão de que o valor de um bem embora resultando da utilidade depende da quantidade dêsse bem, porque é ela que determina a última necessidade que pode ser econômicamente satisfeita, e é pela utilidade da última fração que se mede o valor de qualquer das unidades que formam o total da provisão.

Tanio o marginalismo como o seu sucessor, o neomarginalismo, sofreram o aguilhão da crítica demolidora e sem misericórdia. Matos Peixoto (ob. cit., pág. 81) citando a observação de Henri Truchy de que a utilidade-limite, desiderabilidade ou utilidade-rara, já foi explicada como sendo «chave que abre muitas portas, mas muitas vêzes portas atrás das quais não há nada», conclui melancòlicamente: «O que é muito de assinalar é ter ido dar o marginalismo, ao fim de tudo, a um simples truísmo».

Em seu excelente estudo sôbre o marginalismo (o antigo e o nôvo), Gä̈TAN PIRou (ob. cit.) faz uma minuciosa exposição da crítica partida dos socialistas, dos institucionalistas norte-americanos e dos homens de ciência, para concluir que, «feito o balanço da crítica e dos acertos, o neomarginalismo se ganhou em certeza talvez tenha perdido em clareza». E, se do marginalismo só resta a idéia central de «margem»: custo marginal, desejo marginal, produtividade marginal, etc., e se o neomarginalismo (remata o prof. PIRou) tornou-se uma teoria neutra, objetiva, sintética, social, dinâmica, que resta do seu conteúdo original?»

\section{VII - CONCLUSÕES}

Ao término de nosso trabalho julgamos ter atingido o intento que nos guiou nesta dissertação: dar a idéia geral do valor econômico, expondo, na medida de nossas limitaçõés, as duas principais teorias que pretendem resolver o problema do valor. As demais não lograram a repercussão daquelas (valor-trabalho e marginalismo), exceto, talvez, a teoria do valor baseado no custo de produção, que é, aliás, um desdobramento natural da teoria do trabalho-valor; e a da oferta e procura, no estado atual da evolução do pensamento econômico, mais se entrosa no estudo do problema do preço: sua formação e variações.

Sendo assim, de tudo quanto se expôs, concluímos:

a) A idéia de valor é fundamental à economia de troca; b) O conceito de valor de uso deve ser amplo, para nêle
se conter o valor estimativo;

c) O valor de uso está na base do valor de troca;

d) A utilidade está para o valor de uso assim como o custo de produção está para o valor de troca; 
e) O trabalho, na economia moderna, de primazia do capital, perdeu a importância primitiva na formação do valor, para reduzir-se a um dos fatôres do custo de produção;

f) A raridade, em seu sentido econômico, atua independentemente na valorização, quer se trate da economia individual (valor de uso) quer se trate da economia social (valor de troca);

g) Sendo uma relação entre duas riquezas permutadas, o valor não se expressa simplesmente na utilidade e sim na relação entre a utilidade (procura) e a quantidade do bem (oferta);

h) O unilateralismo das teorias explicativas do valor econômico impede a solução do problema, e

i) Impõe-se, portanto, a construção de uma teoria geral, que, pela coordenação ou conjunção dos elementos subjetivos e objetivos, elimine o antagonismo das concepções unicausais do valor econômico. 